\title{
Effects of Livestock Grazing on Mearns Quail in Southeastern Arizona
}

RICHARD L. BROWN

Abstract

Grazing by domestic livestock does not limit production of food supplies for Mearns quail (Cyrtonyx montezumae mearnsi) in southeastern Arizona. Nevertheless, grazing available forage in excess of $55 \%$ by weight can nearly eliminate local quail populations by removing their escape or hiding cover just prior to the nesting season. This eliminates the breeding population itself. The 46 to $50 \%$ level of utilization by weight appears to be marginal for maintaining optimum quail populations.

The Mearns quail is the northernmost of three subspecies collectively known as montezumae quail. These are endemic to the pine-oak vegetation zone of Mexico with the range of C.m. mearnsi subspecies extending into portions of southern Arizona, New Mexico, and west Texas (Leopold and McCabe 1957). Arizona's population is distributed from the Mexican border north to the Mogollon Rim and from the Baboquivari Mountains east to New Mexico (Fowler 1903 in Bishop 1964, Yeager 1966). Major populations are located in the southeastern corner of the state in the oak woodland and grassland described by Lowe (1964).

In 1960 the Mearns quail was legally hunted for the first time in Arizona, and since then has become a focal point for attention from preservationists and hunters alike. The limited amount of literature on the species frequently refers to the negative effect that livestock grazing has on quail densities. However, no previous investigator brought quantitative evidence to bear on the subject, and there was a lack of agreement among investigators on how grazing actually limited populations. Leopold and McCabe (1957) felt that grazing depleted the birds' food supply. Ligon (1927) felt the problem was related to cover removal. It is the intent of this paper to explain the mechanics of the relationship between livestock grazing and quail densities and to estimate the level of grazing intensity that is limiting to local quail populations.

\section{Methods}

Information on Mearns quail food production under different levels of grazing intensity was gathered over a 9-year period. Food production ( $\mathrm{gm} / \mathrm{ha}$ ) was estimated semiannually from stem counts of preferred Mearns quail food items on $1889.3 \mathrm{~m}^{2}\left(100 \mathrm{ft}^{2}\right)$ plots. Analysis of crop contents from collected quail dictated items to be included in stem counts. Plots were distributed among 4 different adjacent cattle pastures, each of which was grazed at a different level of intensity. Mearns quail were censused (Brown 1976) annually on these pastures.

Four other small study areas were also censused for quail in June and early July to determine the presence or absence of mated pairs within represented forage production and utilization zones. Grass

\footnotetext{
The author is research biologist, Arizona Game and Fish Department, P.O. Box 480, Fredonia, Arizona 86022 .

These studies were funded entirely under provisions of the Federal Aid in Wildlife Restoration Act, Project W-78-R, Arizona Game and Fish Department.

Author's thanks go to Chuck Shipp, Coronado National Forest, for the conduct of certain of the forage production estimates. Also greatly appreciated is the help of Larry and Barbara Robbins, owners of the Little Outfit Ranch, and John Gates, foreman of the Heady Ash burn Ranch, for cooperation in establishing the initial study areas.

Manuscript received November $16,1980$.
}

production estimates were made on all areas according to procedures outlined in the U.S. Forest Service Handbook for Range Environmental Analysis (1970); and 2nd estimates of forage utilization by livestock were made to the nearest $5 \%$ (Roach 1950).

Grass production estimates were placed on maps of the study areas and isometric lines were drawn at $36.6 \mathrm{~kg} / \mathrm{ha}(200 \mathrm{lb} /$ acre $)$ increments. Estimates of forage utilization by livestock, isometrically mapped in $5 \%$ increments, were then superimposed on the forage production maps. The final isometric maps included both production and utilization zones and represented a total of 1755 ha $\left(6.75 \mathrm{mi}^{2}\right)$ for all study areas combined. Forage production estimates were not measured on 562 ha thus classified. Production estimates for this area were derived from an immediately adjacent but smaller area of similar vegetative composition and crown cover and projected to this 562 ha with minor adjustments for differences in precipitation patterns.

A map of quail home ranges was overlaid on the productionutilization map. With this approach, it was then possible to relate pair density to production-utilization categories. When a pair home range overlapped more than a single production-utilization zone, both production and utilization were estimated for that home range as a weighted average.

All areas sampled were assumed to be capable of sustaining medium to high densities of quail under normal climatic conditions. This assumption is based on the fact that these areas contained requisite tree cover, and that the general area had sustained continuous populations of Mearns quail. Only wooded areas with $20 \%$ or greater crown cover (oak and/or manzanita), and open grassland within $45.7 \mathrm{~m}$ of such overstory were used. Leopold and McCabe (1957) have reported ".... heavy populations (of Montezumae quail) in second growth scrub...", and have stated, "....condition of the forest canopy doesn't seem to matter...". It is doubtful, however, that they intended this to mean a total absence of large overstory. General observations made during the course of the studies reported herein indicate that Mearns quail in southeastern Arizona do not inhabit open grasslands. They inhabit wooded areas and use adjacent areas of open grassland. Open areas 0 to $22.9 \mathrm{~m}$ from the tree line were heavily used; areas 22.9 to $45.7 \mathrm{~m}$ ( 25 to $50 \mathrm{yds}$ ) were used less frequently. Sightings of birds or scratchings over $45.7 \mathrm{~m}$ from tree lines were unusual. Therefore, all surface area recorded in Table 4 can be considered medium to high quality Mearns quail habitat in this respect. The $20 \%$ crown cover figure is a value arbitrarily derived for the purpose of this study. Relating crown cover to quail density was beyond the scope and capabilities of the study. However, there is some indication that areas with $30 \%$ or more crown cover tended to sustain higher densities of quail than those with only 20 . Only 22.3 ha of the area recorded in Table 4 had between 20 and $30 \%$ crown cover.

All study areas were located within the $1400-2000 \mathrm{~m}$ altitudinal range in the oak woodland and grassland (Lowe 1964) of the eastern foothills of the Santa Rita Mountains, Canello Hills, and Patagonia Mountains of Santa Cruz County, Ariz. (Fig. 1). The overst ory consists mainly of Quercus arizonica and $Q$. emoryi with varying amounts of manzanita (Arctostaphylos sp.) in some areas. The grass community is almost exclusively a summer-growing 


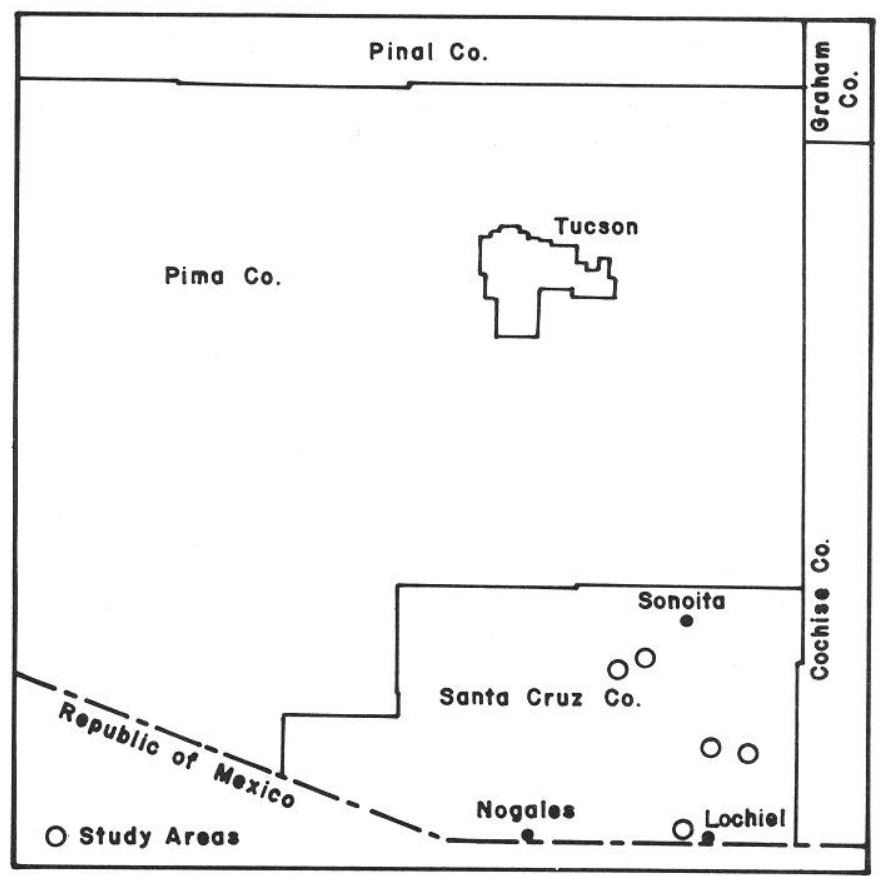

Fig. 1. Map of Mearns quail study areas.

perennial bunch grass type. Areas consistently grazed below the $35 \%$ level of utilization by weight are dominated by Bouteloua curtipendula and Andropogon barbinodis, with one of the study areas supporting large amounts of Texas bluestem (Andropogon cirratus). Steep north-facing slopes have substantial amounts of bullgrass (Muhlenbergia emersleyi). The most heavily grazed areas are dominated by Bouteloua hirsuta, B. gracilis, and Aristida ternipes. Topographically, the areas tend to be broken by numerous small canyons with slopes of 20 to $45^{\circ}$. North-facing slopes are heavily wooded with oak. Southern exposures and flatter portions tend to be open grassland (Fig. 2).

Most of the annual precipitation in this area is received during the summer monsoon season. Yearly precipitation measured at the Heady Ashburn Ranch near one of the study areas $3.2 \mathrm{~km}$ (2 miles) west of Lochiel, Santa Cruz County, averaged $45.2 \mathrm{~cm}$ for the 15-year period 1961-75. Sixty-eight percent of this fell during the June-September period, $21 \%$ during the December-March period, and the remaining $11 \%$ was received intermittently during the April-May and October-November periods.

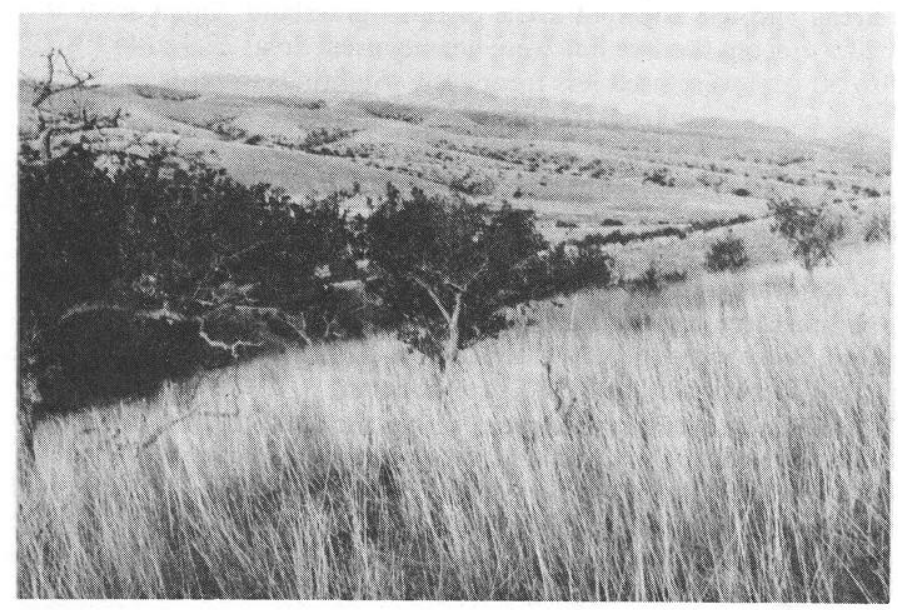

Fig. 2. Mearns quail habitat, Santa Cruz county, Ariz.

\section{Results}

Effects of Grazing on Mearns Quail Food Production

Plant species encountered during examination of Mearns quail crop contents are listed in Table 1. Average annual quail food production estimates (Table 2, which contains all Table 1 species combined) correlated ( $r=0.905 p \leq .10)$ with forage utilization estimates made on forage plots within those pastures. The more heavily grazed pastures were also the most productive. The severely grazed portion of the Clopton pasture (Table 2 ) produced nearly twice as much quail food as the moderately grazed Heady Ashburn pasture. A similar comparison can be made between the Clopton and the De La Ossa-Duquesne pasture. They are adjacent to each other and edaphically similar, yet the Clopton pasture produced the most quail food. The USDA Forest Service Range environmental Analysis Handbook (1970) classified all species in Table 1, except Phaseolus acutifolius and Galactia wrightii, as increasers or invaders on grazed pastures. In the Lochiel study, Galactia was the only species found solely in association with climax stands of grass and Phaseolus acutifolius appeared unaffected by grazing.

With the exception of Arctostaphylos sp., which is not a significant Mearns quail food under most conditions (Bishop and Hungerford 1965), all food items listed in Table 1 grow during the summer.

There is indeed a potential for grazing to reduce food supplies immediately through the removal of seed, but this potential seems slight. Three of the production estimates (seed production for Cyperus rusbyi, C. mannimae, and Paspalum stramineum) have been adjusted upward to compensate for amounts estimated to have been grazed during the summer growing season. However, in aggregate these adjusted figures comprise only $23.5 \%$ of the overall quail food production and only a portion of this would be grazed before the seed fell. Other items in Table 1 are either not grazed at all, or are grazed very lightly while contributing little to either the overall diet or production estimates. The underground bulbs of Oxalis amplifolia and Cyperus rusbyi combined, comprised $76.6 \%$ of the crop contents and $69.3 \%$ of the total food production. These of course would not be removed by grazing at any time of the year. Clearly, livestock grazing has not limited Mearns populations on these study pastures through reducing their food supply. In fact, the available information suggests that grazing is actually beneficial to Mearns quail in this respect.

Table 1. Mearns quail food items and food production estimates, Lochiel study area.

\begin{tabular}{|c|c|c|c|c|}
\hline \multirow{3}{*}{ Species } & \multicolumn{2}{|c|}{$\begin{array}{l}\text { Air-dry wt. crop } \\
\text { analysis } 1967-77 \\
\text { (188 crops) }\end{array}$} & \multicolumn{2}{|c|}{$\begin{array}{l}\text { Avg. annual } \\
\text { production } \\
1968-1976 \\
\end{array}$} \\
\hline & Tart & & Gms/ & \\
\hline & Part & $\%$ & hectare & $\%$ \\
\hline \multirow[t]{2}{*}{ Cyperus rusbyi } & bulb & 50.7 & 11,148 & 67.6 \\
\hline & seed & 0.3 & 2,538 & 15.4 \\
\hline Cyperus mannimae & seed & unk $^{\prime}$ & 81 & .5 \\
\hline Oxalis amplifolia & bulb & 25.9 & 272 & 1.7 \\
\hline Paspalum stramineum & seed & 7.5 & 1,251 & 7.6 \\
\hline Galactia wrightii & seed & 3.5 & 36 & 0.2 \\
\hline Phaseolus acutifolius & seed & 3.1 & 212 & 1.3 \\
\hline Tephrosia tenella & seed & 1.8 & 2 & .01 \\
\hline Ipomea sp. & seed & 1.2 & 2 & \\
\hline Arctostaphylos sp. & flower \& fruit & 0.8 & 2 & \\
\hline Euphorbia dentata & seed & 0.6 & 10 & 0.1 \\
\hline Panicum capillare & seed & 0.2 & 2 & \\
\hline Ambrosia psilostachya & seed & 0.1 & 921 & 5.6 \\
\hline Phaseolus heterophyllus & seed & $\operatorname{tr}$ & 22 & .1 \\
\hline Vitis arizonica & seed & $\operatorname{tr}$ & 2 & \\
\hline \multirow[t]{2}{*}{ Miscellaneous } & seed \& tuber & 4.3 & 2 & \\
\hline & & $\overline{100.0}$ & $\overline{16,493}$ & $\overline{100.11}$ \\
\hline
\end{tabular}

'Seed cannot be differentiated from seed of C. rusbyi.

${ }_{2}^{2}$ Production not measured. 
Table 2. Estimated Mearns quail food production, livestock utilization levels and fall covey densities (annual averages Lochiel study area).

\begin{tabular}{|c|c|c|c|}
\hline Pasture & $\begin{array}{c}\% \text { plants } \\
\text { grazed on plots } \\
1968-76\end{array}$ & $\begin{array}{l}\text { Quail food } \\
\text { produced } \\
\text { gms/hectare } \\
1968-76\end{array}$ & $\begin{array}{c}\text { \# coveys } / \mathrm{km}^{2} \\
1971-76\end{array}$ \\
\hline Heady Ashburn & 50 & 10,900 & 10.3 \\
\hline $\begin{array}{l}\text { De La Ossa } \\
\text { (Lochiel Pasture) }\end{array}$ & 70 & 13,400 & 8.1 \\
\hline $\begin{array}{l}\text { De La Ossa } \\
\text { (Duquesne Pasture) }\end{array}$ & 73 & 12,500 & $9.6^{1}$ \\
\hline Clopton & 91 & 21,200 & 0.0 \\
\hline
\end{tabular}

1973 through 1976 only.

Nevertheless, the conclusion that grazing can limit Mea rns quail populations is unavoidable. Apparently, some critical threshold level of grazing was exceeded on the Clopton pasture which was the most heavily grazed and produced the most quail food, yet failed to successfully harbor any quail for the entire duration of the study (Table 2). This demonstrates that livestock grazing prevented the establishment of Mearns quail on this pasture through the removal of cover rather than by limiting the quails' food supply.

Effects of Cover Removal on Mearns Quail Populations

Excessive cover removal could affect the population in either or both of two ways. It could limit nest building itself. The nest usually has an overhead canopy of grass stems (Wallmo 1954). It could also limit the population through the removal of necessary

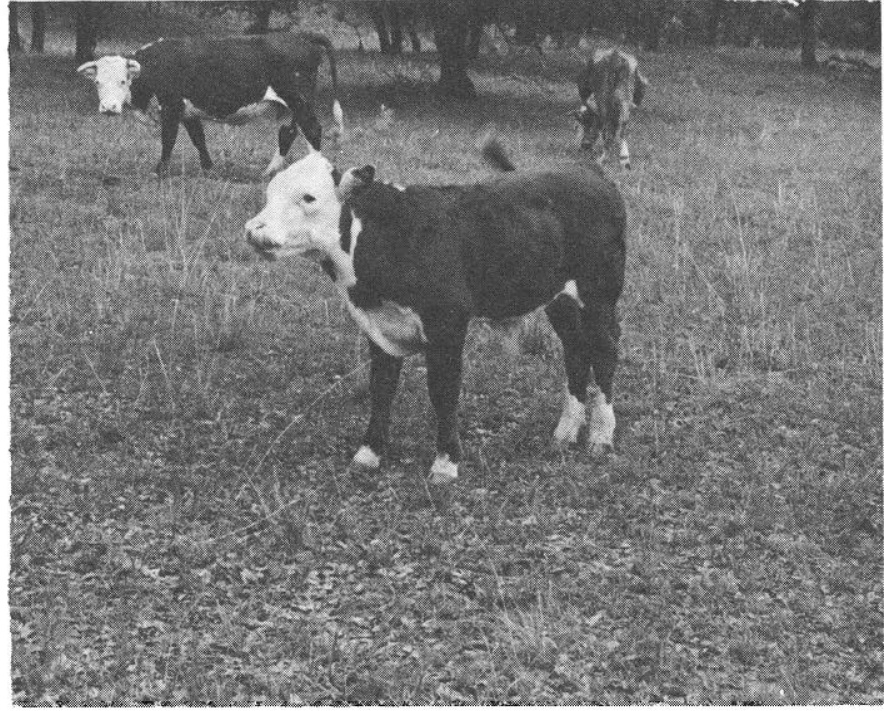

Fig. 3. Height of new vegetation material, July 28, 1976, Lochiel Study Area. Note visibility of hooves.

escape cover. In the latter case, survival of individuals is directly and immediately threatened. This would occur at a time of year when the quail population is at its annual low point and therefore extremely vulnerable to any further loss of birds.

Nesting is underway before regrowth of new vegetation has

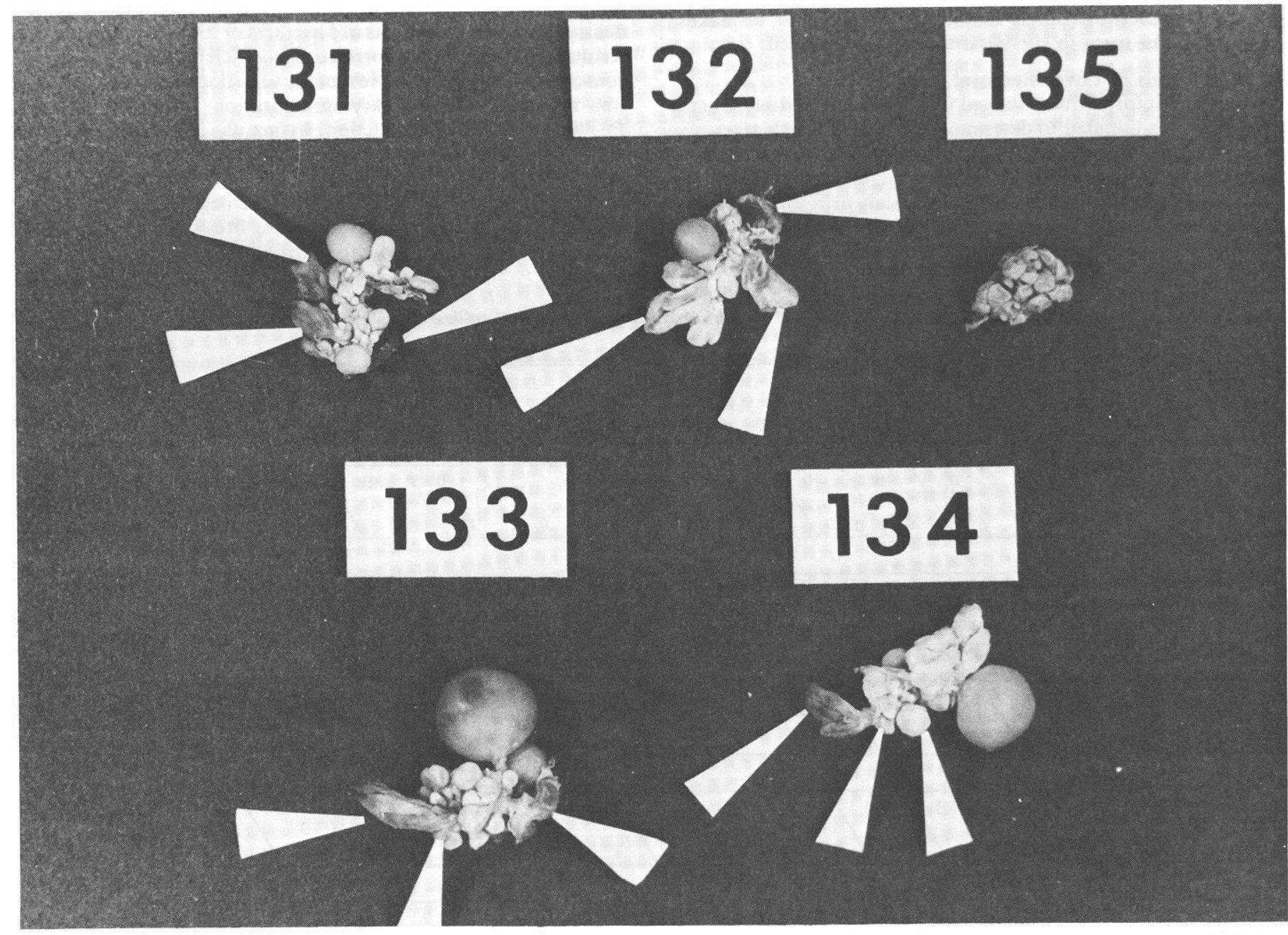

Fig. 4. Reproductive tracts from Mearns quail shot July 21-30, 1976, Lochiel Study Area. Empty follicular envelopes are recognizable in birds No. 131-134. 
progressed to the point that it provides adequate cover for either nesting or escape (Fig. 3 and 4), and quail must rely on cover from the previous summer growing season. At the time of the Figure 3 photograph, new growth height was $152-177 \mathrm{~mm}$ for blue (Bouteloua gracilis) and sideoats grama ( $B$. curtipendula). Hairy grama (B. hirsuta) was $76-102 \mathrm{~mm}$. Five female Mearns quail were collected in July of 1976. Numbers 131 and 132 are in the post ovulating stage (Fig. 4). Number 133 was post ovulation or ovulating and 134 was ovulating. The ovary from bird number 135 did not have identifiable empty follicular envelopes; however, the oviduct diameter, $10.0 \mathrm{~mm}$ at its widest point, suggests that laying had already terminated. Oviducts from pre-ovulating birds are usually about $3 \mathrm{~mm}$ in diameter.

The Clopton pasture not only failed to harbor any fall coveys permanently; it failed to harbor any mated pairs initially (Table 3). The adjacent more lightly grazed De La Ossa-Duquesne pasture habored both mated pairs and fall coveys during all years. The lack of mated pairs on the Clopton pasture confirms that the initial impact of cover removal is on the breeding population itself. The lack of fall coveys was due primarily to absence of an initial breeding population. During the study, two fall coveys from the De La Ossa pasture are known to have partially encroached upon the Clopton pasture for a short period of time. But, cover was removed so rapidly by grazing on the Clopton pasture that both coveys were forced back onto the De La Ossa pasture by mid-winter. This occurred at a time of the year when food supplies were high and nest material unimportant, thus indicating that lack of escape cover was the critical factor. It scems likely then that the same mechanism prevents breeding populations from becoming established. Apparently, lack of escape or hiding cover discourages mated pairs from becoming established initially and/or makes it impossible for them to survive if they are established.

\section{Critical Levels of Cover Removal}

Based on information obtained from the Lochiel study, a separate study was initiated to determine the level at which grass cover removal by livestock becomes critical to the establishment and survival of Mearns quail breeding populations. Data were gathered from portions of the Lochiel study area and three other small areas from 1973-1976. A fifth study area yielded data from 1970-6. The occurrence of mated pairs, classified according to
Table 3. June breeding densities and forage utilization levels on two adjacent pastures-Lochiel study area. ${ }^{2}$

\begin{tabular}{|c|c|c|c|c|}
\hline \multirow[b]{3}{*}{ Year } & \multicolumn{4}{|c|}{ Pastures } \\
\hline & \multicolumn{2}{|c|}{ Clopton } & \multicolumn{2}{|c|}{ De La Ossa (Duquesne) } \\
\hline & Pairs $/ \mathbf{k m}^{2}$ & $\begin{array}{c}\% \text { Plants } \\
\text { grazed on } \\
\text { forage plots } \\
(N=38)\end{array}$ & Pairs $/ \mathrm{km}^{2}$ & $\begin{array}{c}\% \text { Plants } \\
\text { grazed on } \\
\text { forage plots } \\
(\mathrm{N}=33)\end{array}$ \\
\hline 1968 & 0 & 65 & 1 & 53 \\
\hline 1969 & 0 & 87 & 1 & 60 \\
\hline 1970 & 0 & 94 & 1 & 69 \\
\hline 1971 & 0 & 96 & I & 80 \\
\hline 1972 & 0 & 95 & 21.3 & 75 \\
\hline 1973 & 0 & 94 & 17.1 & 77 \\
\hline 1974 & 0 & 95 & 8.5 & 77 \\
\hline 1975 & 0 & 95 & 8.5 & 86 \\
\hline 1976 & 0 & 90 & 8.5 & 78 \\
\hline
\end{tabular}

IMated pairs present but in unknown number. Pasture used for induced calling 1968 and for collecting 1969-71.

${ }^{2}$ Average bunch grass production (1972-1975): Copton-54.0 kg/ha, De La Ossa$117.3 \mathrm{~kg} / \mathrm{ha}$.

weighted averages of production and utilization categories within their home ranges, was the criterion used to determine the suitability of these production and utilization zones for quail occupancy.

The correlation analysis was conducted where pair density ( $\mathrm{pr} / \mathrm{ha}$ ) was the dependent variable and means of the production and utilization categories (Table 4) were independent variables. The pair density estimates entered into the calculations were not weighted for the number of hectares samples, although any pair density estimates from a reas of 5 hectares or less were not used. The resultant multiple linear correlation coefficient was highly significant $(R=0.685, P \leq .01)$. Most of the variation in quail pair density was accounted for by varying utilization levels $(r=-0.653$, $P \leq .005)$ rather than production. In fact, the partial correlation of quail pair density and production category was only 0.271 (n.s.) after adjusting for utilization level.

It appears from the foregoing that the degree of utilization by livestock is the overriding factor limiting Mearns quail pair density and not the inherent productivity of an area.

Table 4. Hectares sampled and numbers of mated pairs of Mearns quail by production and utilization category. (percent utilization by weight)

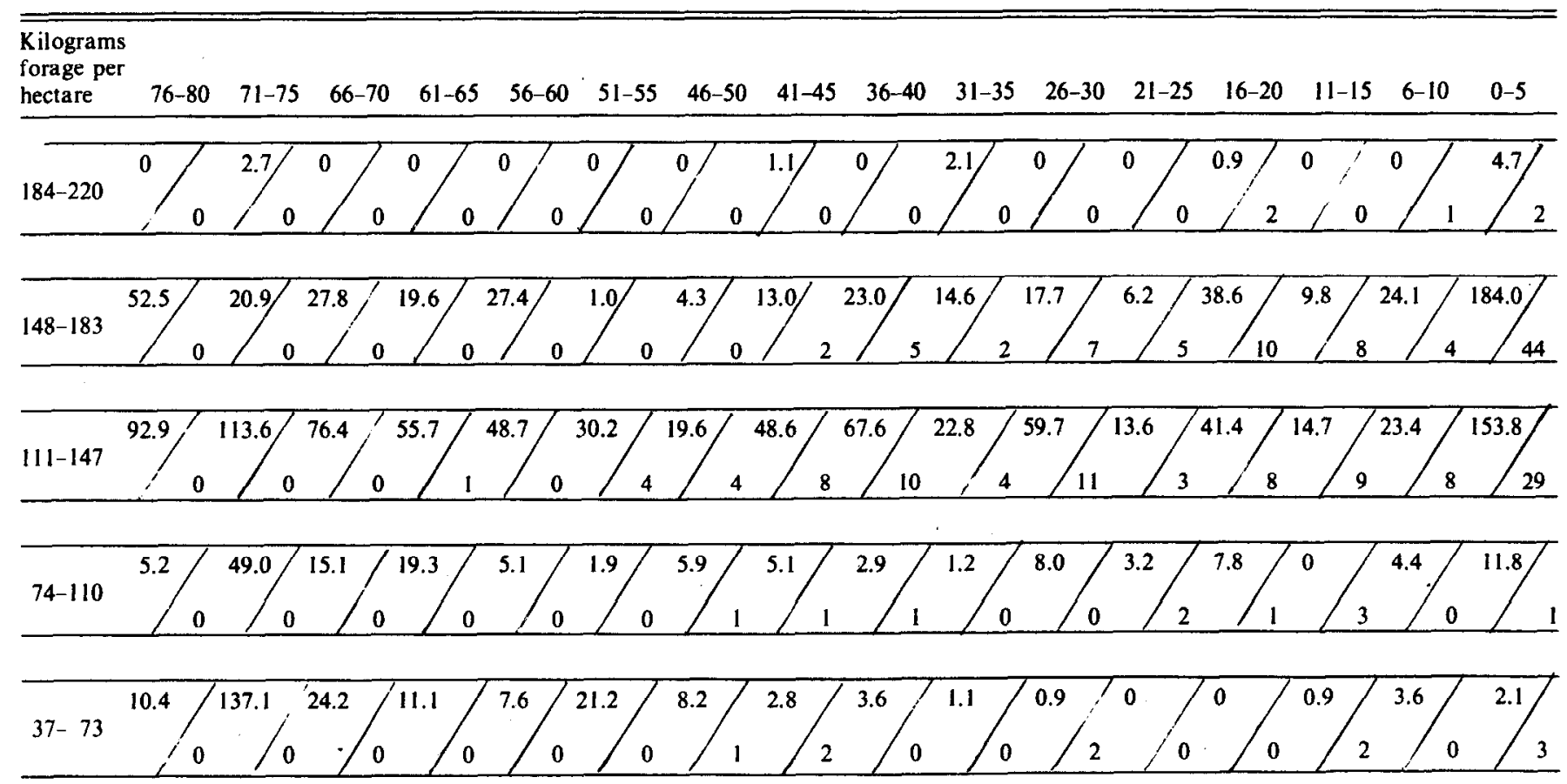


Ninety-five percent of the mated pairs censused were found on areas having average utilization levels of $45 \%$ by weight or less for their entire home range, and $98 \%$ occurred at or below the $50 \%$ by weight level (Table 4). Only $2 \%$ of the pairs encountered occurred on a reas whose average level of utilization was above $50 \%$ despite the fact that $49.7 \%$ of the ground sampled was grazed in excess of that point. The 46 to $50 \%$ by weight level, therefore, appears to be marginal for maintaining optimum population levels.

The Table 4 data possess one obvious peculiarity-the absence of mated pairs in areas of the $184-220 \mathrm{~kg}$ /ha production zone which were grazed in excess of the $20 \%$ by weight utilization level. This can probably be attributed to light sampling of ground area representing this production level. If a $111-147 \mathrm{~kg} /$ ha production zone will harbor mated pairs at the 46 to $50 \%$ level of utilization, then one could expect a higher production zone to do at least that well. However, during average years, the $184-220 \mathrm{~kg} /$ ha production zone represents a relatively small portion of the Mearns quail habitat as suggested by Table 4 . Only 11.43 ha, or less than $1 \%$ of the total habitat sampled as part of this study, was represented by this production range. Seventy-eight percent of the total habitat sampled fell within the $111-184 \mathrm{~kg} / \mathrm{ha}$ range, and it is this production range that deserves the primary attention. Within this production range, the 45 to $50 \%$ utilization range is marginal for Mearns quail.

\section{Discussion and Recommendations}

The following discussion is somewhat speculative, but is necessary in order to relate the foregoing results on utilization levels to Mearns quail behavior and annual population levels.

General cover conditions are of prime importance to the Mearns quail because of the escape mechanism it employs. Its initial reaction to danger is to "freeze." This characteristic is so highly developed that the quail will usually resort to it even in the middle of an asphalt road when approached by an automobile. Although effective in dense cover, the escape mechanism becomes useless, or even detrimental, once grass cover has been seriously reduced.

The perennial bunch grasses that serve as Mearns quail cover are strictly summer-growing species produced during the July-September period. Forage utilization levels from livestock grazing begin to develop in October and reach their maximum by around June 30 of the following year.

Bishop (1964) reported that Arizona Mearns quail form pair bonds as early as late February and that most quail are paired by the end of March. However, most nesting is delayed until late June or July and most broods appear in August. Information gathered under the studies reported herein is basically in agreement. Most pairing occurs during March and April, and most nesting occurs between late June and mid-August. Bishop (1964) felt that the family unit remained intact as an individual covey until time of covey break-up the following March or thereabouts, and that the covey tends to occupy the same piece of ground occupied by the mated pair. It is extremely difficult to verify adequately either of these two premises; however, observations I have made suggest both are generally correct, provided that adequate supplies of food and cover persist (Brown 1978). Following break-up of the covey, an area which during the winter months harbors a group of approximately 8 birds, harbors only $2-$ a mated pair. This is most likely the result of territorial behavior on the part of the male. The territory is probably a "Class A" territory, as defined by Nice (1941), containing all feeding areas as well as the nesting area. Territoriality is therefore suspected of setting density limits on the breeding population. If so, nonterritory-holding individuals are forced into areas which contain either inadequate food or cover.

The spatial factor, whether territorially maintained or not, does exist between mated pairs, and this seems to prevent population compression beyond a certain point. Under normal or stable yearto-year conditions, mated pair densities in June more closely approximate previous winter covey densities than a three-fold increase from that level (Table 5). The latter condition would, of
Table 5. June mated pairs and winter covey densities.

\begin{tabular}{llcc}
\hline \hline Summer & Study area & No. pairs & $\begin{array}{c}\text { No. coveys } \\
\text { previous } \\
\text { winter }\end{array}$ \\
\hline 1972 & Big Casa Blanca Canyon & 32 & 15 \\
1973 & Big Casa Blanca Canyon & 40 & 36 \\
1974 & Big Casa Blanca Canyon & 35 & 13 \\
1975 & Big Casa Blanca Canyon & 34 & 23 \\
1970 & Little Outfit Ranch & 21 & 20 \\
1971 & Little Outfit Ranch & 19 & 21 \\
1973 & Dixie Mine & 6 & 13 \\
1974 & Dixie Mine & 4 & 5 \\
1975 & Dixie Mine & 9 & 7 \\
1976 & Dixie Mine & 9 & 10 \\
1976 & Lochiel (Heady Ashburn and & 38 & 31 \\
& De La Ossa Lochiel Pastures) & & \\
\hline
\end{tabular}

course, exist if most members of a winter covey of 8 birds becamc successfully established and survived. ${ }^{1}$ This situation existed in Big Casa Blanca Canyon during 1972 and 1974 following winters when populations were depressed. The remaining census data from other areas or during other years were obtained when population levels were relatively stable on those respective areas. During such years, surviving surplus individuals from these areas are obviously forced into less desirable arcas, many of which contain either inadequate food or cover. Their immediate problem becomes one of survival, and this negates the possibility of delaying nesting until regrowth of new vegetative material provides additional cover.

The fate of these nonestablished birds has not been documented. If they are forced into an area containing inadequate food, starvation becomes a factor. And undoubtedly it is a major factor, since annual food supplies a re at their lowest point during this time of year (Leopold and McCabe 1957, Bishop and Hungerford 1965 , Brown 1978). Quail which choose the other horn of the dilemna and move into areas which have adequate supplies of underground bulbs and tubers, but which are denuded of grass cover, probably become prime targets for raptors. Data on this source of quail loss are extremely difficult to obtain. Only 6 cases of suspected avian predation on a mated pair member were documented during the study. However, only one of these occurred within what is considered to be a zone with adequate cover; an area producing about $147 \mathrm{~kg}$ of forage/ha, 5 to $10 \%$ of which had been removed by livestock grazing. The other 5 cases of predation occurred in completely denuded areas. Three of these were within $18.3 \mathrm{~m}$ of adequate cover which the quail had left during their foraging activities. Most cases of predation have been confirmed from the evidence left. Only one case of avian predation was actually witnessed and was caused by a sharp-shinned hawk (Accipiter striatus). These small hawks were common in areas where the study was conducted as were the larger Accipiter cooperii.

The vulnerability of the population to the loss of birds during late May and June has been demonstrated artificially through the collecting of mated pairs. During the studies reported herein, a number of mated pairs were collected during spting or early summer around the periphery of the Lochiel study area over a period of 9 years. Subsequent fall censuses showed that the impact of the collecting was so severe that it could not be done in any area to be used for a population study. Areas that were used for this purpose had consistently and proportionally depressed numbers of fall coveys. If one or both members of a mated pair was collected during March or April, a single or another pair usually appeared to fill the vacancy. When a pair was collected in May or June, however, usually no replacement appeared during that nesting season. This was documented on a small scale in 1975. On an area just north of Lochiel study area that was known to contain 5 mated pairs, both members of one pair were shot during mid-April. Both members of two more pair and the female from another pair were collected during early June. A November census of the area revealed two resident coveys. Bishop (1964) reported destroying 4 
pairs bonds by collecting 6 birds from a population of 9 original pairs during mid-July. This resulted in only 5 , or possibly 6 , coveys being present the following fall. These 2 sets of data, in conjunction with general impressions obtained during the overall collecting program in the Lochiel area, suggest that few replacement birds are available at the outset of the nesting season, and the destruction of a pair bond at that time, or just prior, usually results in the loss of a fall covey. Avian predation would, of course, have the same effect.

Regardless of whether the foregoing hypotheses are entirely correct, the evidence demonstrates that cover removal resulting from grazing can nearly exterminate a quail population if utilization levels exceed $55 \%$ by weight in an evenly distributed pattern. From the standpoint of maintaining breeding populations, excessive utilization levels which develop at one time of the year are equally detrimental to those which develop at another. If they develop in December, they will still be present in May and June, since the grass community is comprised solely of summer-growing species. Excessive utilization levels which develop by mid-winter can, of course, displace resident winter coveys; however, this is not the primary problem.

Forage production levels, and subsequent utilization levels under stable stocking rates, vary considerably from year to year as a result of varying amounts and distribution of precipitation. Recommended utilization levels must, therefore, be below the $51-55 \%$ range to compensate for dry years. While the 40 to $45 \%$ level of utilization provides a slight safety margin and should adequately compensate for minor fluctuations in forage production during most years, the 35 to $40 \%$ range is preferable as it provides some additional protection for years of extremely low forage production. As suggested by the study approach, this recommendation applies only to wooded areas and open grassland within about $46 \mathrm{~m}$ of this tree overstory.

\section{Literature Cited}

Bishop, R.A. 1964. The Mcarns Quail (Cyrtonyx monte zumae mearnsi) in southem Arizona. MS thesis, Univ. Ariz., Tucson, 82 p.

Bishop, R.A., and C.R. Hungerford. 1965. Seasonal food selection of Arizona Mearns quail. J. Wild. Manage. 29:813-819.

Brown, R.L. 1976. Mearns quail census technique. Final Rep. Proj. W-78R-15, WP1/J1. Ariz. Game and Fish Dept. 14 p.

Brown, R.L. 1978. An ecological study of Mearns quail F.A. Rep. Proj. W-78-R-22, WP2/J1. Ariz. Game and Fish Dept. 26 p.

Fowler, F.H. 1903. Stray notes from southern Arizona. Cond or, 5:68-71.

Leopold, A.S., and R.A. MeCabe. 1957. Natural history of the Montezuma quail in Mexico. Condor 59:3-26.

Ligon, J.S. 1927. Wildlife of New Mexico; its conservation and management. New Mexico State Game Comm., Santa Fe. 212 p.

Lowe, C.II. 1964. Arizona's natural cnvironment. Univ. Ariz. Press. 136 p.

Nice, M.M. 1941. The role of territory in bird life, Amer. Midl. Natur. 26:441-487.

Roach, M.E. 1950. Estimating perennial grass utilization on semi-desert cattle ranges by percentage of ungrazed plants. J. Range Manage. 3:182185.

USDA Forest Service. 1970. Range environmental analysis handbook. Region 3, Albuquerque, N.M.

Wallmo, O.C. 1954. Nesting of Mearns quail in southeastern Arizona. Condor 56(3): 125-123.

Yeager, W.M. 1966. Means quail management information. Spec. Rep. F.A. Proj. W-53-R-16, Ariz. Game and Fish Dept. 22 p.

\title{
RANGELAND HYDROLOGY
}

\author{
by Farrel A. Branson, Gerald F. Gifford, Kenneth G. Renard, and \\ Richard F. Hadley
}

Unique in its emphasis on the hydrology of rangelands, primarily arid and semiarid lands, RANGELAND HYDROLOGY provides a text for one aspect of range management where none has existed before. This expanded Second Edition presents in-depth information for those who must manage rangeland or respond to questions about the impacts of land use practices on hydrology.

Included in the new Second Edition are a chapter on modeling with approaches to predicting the effects of land use, and a chapter on the rapidly developing field of snow pack management.

The 352-pages include 197 illustrations, providing rapid access to an assembly of data found nowhere else and useful in the preparation of environmental impact statements. Extensive bibliog raphic material with each chapter and a subject matter index add to the useableness of the book.

Range scientists and managers, soil conservation/sts, hydrologists, agricultural engineers, land reclamation specialists, wildlife managers, graduate and undergraduate students and their professors, as well as all interested in the hydrology of arid lands will find RANGELAND HYDROLOGY a valuable addition to their libraries. (352 pages paper laminated cover $\$ 15.00$ US) 